\title{
VAMOS PARA AS RUAS! UMA EXPERIÊNCIA EM AFUÁ, NO ARQUIPÉLAGO DO MARAJÓ, EM JULHO DE 2013
}

\author{
WE GO TO THE STREETS! DEVELOPMENTS IN AFUÁ, A SMALL TOWN \\ IN THE ARCHIPELAGO OF MARAJO IN THE AMAZON, IN JULY 2013
}

VAMOS A LAS CALLES! UN EXPERIMENTO EN EL AFUÁ, ARCHIPIÉLAGO
DE MARAJÓ, EN JULIO DE 2013

\author{
Ivania Neves. \\ Professora do PPGCom UFPA. \\ ivanian@uol.com.br \\ Diogo S. M. de Miranda. \\ Mestrando do PPGCom UFPA. \\ diogo.sm2@gmail.com
}

\begin{abstract}
Resumo
Os protestos nas ruas que marcaram o ano de 2013, no Brasil, caracterizaram-se como um acontecimento intensamente midiatizado. Em menos de uma semana, o descontentamento das primeiras manifestações envolveu, ainda que de formas diferentes, cidades de todas as regiões do país. Na cidade de Afuá, extremo norte da Amazônia brasileira, a principal reivindicação coincidiu com a não realização da Batalha Camaroeira, uma das principais manifestações culturais locais. Em meio às lutas de todo país por educação, saúde, transporte e punição aos corruptos, os afuaenses protestavam também pelo cancelamento da tradicional disputa entre seus grupos folclóricos. Neste artigo, procuramos mostrar como eles se apropriaram deste evento midiático. Para isso, analisamos os processos de interação dos moradores com os meios de comunicação, especialmente a convergência entre as rádios da cidade e a internet.
\end{abstract}

Palavras-chave: Rádios Locais, Primavera Brasileira, Amazônia.

\begin{abstract}
The protests in the streets of Brazil, in 2013, was characterized as a media event. Quickly, the discontent of the first manifestations involved, in different ways, cities in all regions of the country. In the city of Afuá, in the extreme north of the Brazilian Amazon, the main claim coincided with the non-realization of the "Battle shrimp", one of the main cultural sites. They were also unhappy about the issues related to corruption and infrastructure in Brazil, but the townspeople protested against the cancellation of the traditional dispute between their cultural groups. In this article, we show how the townspeople have appropriated this media event. We analyzed the interaction of these residents with the media, especially the convergence between the local radio stations and the World Wide Web.
\end{abstract}

Keywords: Local Radio Station, Spring Brazilian, Amazon. 


\section{Resumen}

Las protestas en las calles que marcaron el año 2013, en Brasil, se caracterizaron como un evento fuertemente midiatizado. En menos de una semana, el descontento de las primeras manifestaciones involucradas, aunque de diferentes maneras, ciudades de todas las regiones del país. En la ciudad de Afua más al norte en la Amazonia brasileña, el principal reclamo coincidió con la finalización de la batalla Camaroeira, una de las principales manifestaciones culturales locales. En medio de las luchas del país para la educación, salud, transporte y castigo a los corruptos, los afuaenses en protesta por la cancelación de la tradicional disputa entre sus grupos folklóricos. En este artículo, se muestra cómo se ha apropiado de este evento para los medios. Para ello, analizamos los procesos de interacción de los residentes con los medios de comunicación, especialmente la convergencia entre las estaciones de radio de la ciudad y el internet.

Palabras clave: Radio local, Primavera brasileña, Amazonas.

\section{SOBRE ESCOLHAS EPISTEMOLÓGICAS}

Sabemos que a internet ocupou um lugar central para o desenvolvimento dos protestos políticos no Oriente Médio que ficaram conhecidos como Primavera Árabe. Da mesma maneira, percebemos que a rede mundial de computadores também ganhou destaque para a realização das manifestações sociais que aconteceram no Brasil, a partir de junho de 2013 - popularmente intitulado como "Primavera Brasileira". As primeiras manifestações, realizadas em São Paulo, motivadas pelo aumento de vinte centavos na tarifa de ônibus, logo ganharam as ruas de todo país. Pela enorme diversidade e complexidade do Brasil, embora trouxessem temáticas comuns, como o combate à corrupção, os protestos se particularizaram pelos usos sociais atribuídos pelos sujeitos locais à web, bem como a relação com outros meios de comunicação.

$\mathrm{Na}$ cidade de Afuá, no extremo norte da Amazônia brasileira, a principal reivindicação local coincidiu com a não realização da Batalha Camaroeira, uma das principais manifestações culturais locais. Em meio às insatisfações das ruas de todo país, que reclamavam por educação, saúde, transporte e punição aos corruptos, na internet, sobretudo no Facebook e na programação das duas rádios locais, os afuaenses protestavam também pelo cancelamento da tradicional disputa entre os grupos folclóricos do Camarão Convencido e do Camarão Pavulagem, em julho de 2013, durante a realização do Festival do Camarão no município.

Para analisar as singularidades das manifestações em Afuá, vamos tomar como referência a formulação de cartografia, proposta por Jesús Martín Barbero (2004). Ele demonstra como a América Latina é entrecortada por uma série de fenômenos sociais que se 
distinguem do restante do planeta pela maneira como se articulam e se organizam entre si. São dinâmicas próprias que formam o substrato que enlaça os indivíduos pertencentes a uma mesma comunidade e modelam aquilo que se conhece como cultura. Assim, ao analisar qualquer fenômeno social nesta parte do globo, entendemos que existe a necessidade de perceber a forma como os sujeitos experienciam essas dinâmicas: como eles ressignificam a lógica de organização de cada fenômeno a partir das particularidades e dos contextos sociais no qual estão inseridos.

De uma maneira geral, as manifestações políticas - como qualquer atividade social guardam em seus acontecimentos uma amplitude de processos que podem ser analisadas a partir de diversas áreas do conhecimento: economia, política, sociologia etc. Mas, ao definir nosso olhar a partir do campo da comunicação, significa que procuraremos perceber as manifestações a partir de um olhar específico, interessado na "natureza comunicativa" de seu acontecimento (FRANÇA, 2001, p. 5): um processo de produção de sentidos que acontece entre os diferentes sujeitos e que está inserido em um contexto específico, sobre o qual a atividade se realiza e se dinamiza a partir de suas peculiaridades.

Assim, neste exercício, para tentar entender os processos comunicativos que residem nas manifestações em Afuá, em julho de 2013, compreendemos que é necessário um deslocamento de nosso olhar para o lugar da experiência desses sujeitos locais. Trata-se de tentar perceber como essas populações vivenciam essas dinâmicas. Estávamos na cidade, quando foi anunciado o cancelamento da Batalha Camaroeira, no início de julho, atentos e abertos aos acontecimentos. Nosso referencial teórico-metodológico de pesquisa se dispõe a fazer uma cartografia das práticas sociais destes moradores, não apenas para identificar as linhas imaginárias de um mapa, mas para sentir como estes acontecimentos foram vividos por eles.

Teremos de deslocar então o olhar, ou melhor, o ponto de vista, para
interrogar a tecnologia a partir desse lugar outro: o dos modos de
apropriação e uso das classes populares. Porque o popular na América Latina
se configura a cada dia com mais força como o lugar desde o qual se torna
possível compreender historicamente o sentido que adquirem os processos
culturais, tanto os que ultrapassam o nacional "por cima" - desde o
funcionamento dos satélites às tecnologias de informação - como os que o
desbordam "por baixo" - desde a multiplicidade de formas de resistência
regionais, étnicas, locais, ligadas à existência negada porém viva de
heterogeneidade cultural (MARTíN-BARBERO, 2004, p. 188).

Nesse sentido, "cartografar" significa para nós a necessidade de observar essa pluralidade de fenômenos que se inscrevem no cotidiano, de perceber as particularidades que 
marcam os contextos sociais que cada realidade empírica guarda em si. Ou seja, não significa escolher antecipadamente um modelo teórico fechado, determinado conjunto de técnicas e optar por caminhos pré-estabelecidos, mas sim, do próprio exercício de dialogar com o objeto empírico. Esta perspectiva permite que o empírico fale por si, revele suas dinâmicas acentuadas e sugira as escolhas metodológicas a serem feitas. Nosso único ponto de partida é o lugar de onde falamos.

O pesquisador deve se apropriar dos instrumentos de investigação já existentes para adequá-los às necessidades que os objetos exijam (MARTÍN-BARBERO, 2004). É dessa maneira que entendemos a atividade de pesquisa como inventora de formas próprias de realizar o estudo, mesmo que para isso utilize instrumentos e técnicas já estabelecidas. Essa metodologia de trabalho, antes de tudo, obriga-nos a realizar um movimento de fazer "nossas" as correntes de pensamentos - de onde quer que venham - para melhor empreendê-las, para utilizá-las de acordo com as necessidades exigidas por cada realidade local.

Além de ser uma prática para se apropriar de conceitos e técnicas já existentes para entender melhor a diversidade sociocultural de cada realidade empírica, compreendemos que a cartografia deve ser também um exercício que atende às particularidades em que se inscreve o pesquisador. Trata-se da utilização de estratégias para ressignificar esses esforços teóricometodológicos a partir das marcas contextuais na qual nos inserimos, para que se possa perceber a complexidade das dinâmicas de cada fenômeno social a partir do lugar de fala do pesquisador.

Assim, compreendemos que se trata de um movimento fundamental para a observação dessa diversidade que tanto se acentua nas muitas realidades latinoamericanas, sobretudo na Amazônia. É dessa forma que desejamos posicionar nosso olhar, para perceber e entender como a cidade de Afuá se distingue como objeto empírico para a realização de pesquisas em comunicação, como um lugar atravessado por inúmeras particularidades sociais, que estão inscritas dentro de um mesmo território e que estabelecem o processo comunicativo de forma diferente de outros lugares da própria Amazônia, do Brasil, América Latina ou qualquer outra parte do planeta.

Para tal exercício, a partir das experiências vividas durante a pesquisa de campo no município de Afuá, procuramos destacar elementos experienciados no cotidiano dos sujeitos da pesquisa. Tais elementos são entrecruzados por "entrevistas informais" junto a alguns moradores que partilharam informações significativas que nos permitiram compreender e vivenciar mais participativamente a sua realidade. 


\section{CARTOGRAFANDO A VENEZA DO MARAJÓ: ENTRE PALAFITAS E BICICLETAS}

O município de Afuá foi fundado no ano de 1869, mas foi apenas em 1890, no período da República, que se emancipou e foi reconhecido como município (FERREIRA, 2003). Atualmente, sua população, está estimada em pouco mais de 35 mil habitantes, distribuídos entre os 6.741 domicílios permanentes existentes e em uma área de pouco mais de 8 mil km², segundo dados do último censo demográfico (IBGE, 2010). No mapa a seguir, a localização do Arquipélago do Marajó e da cidade:

Figura 1: Mapa da localização de Afuá 1 (Fonte: Google Maps).

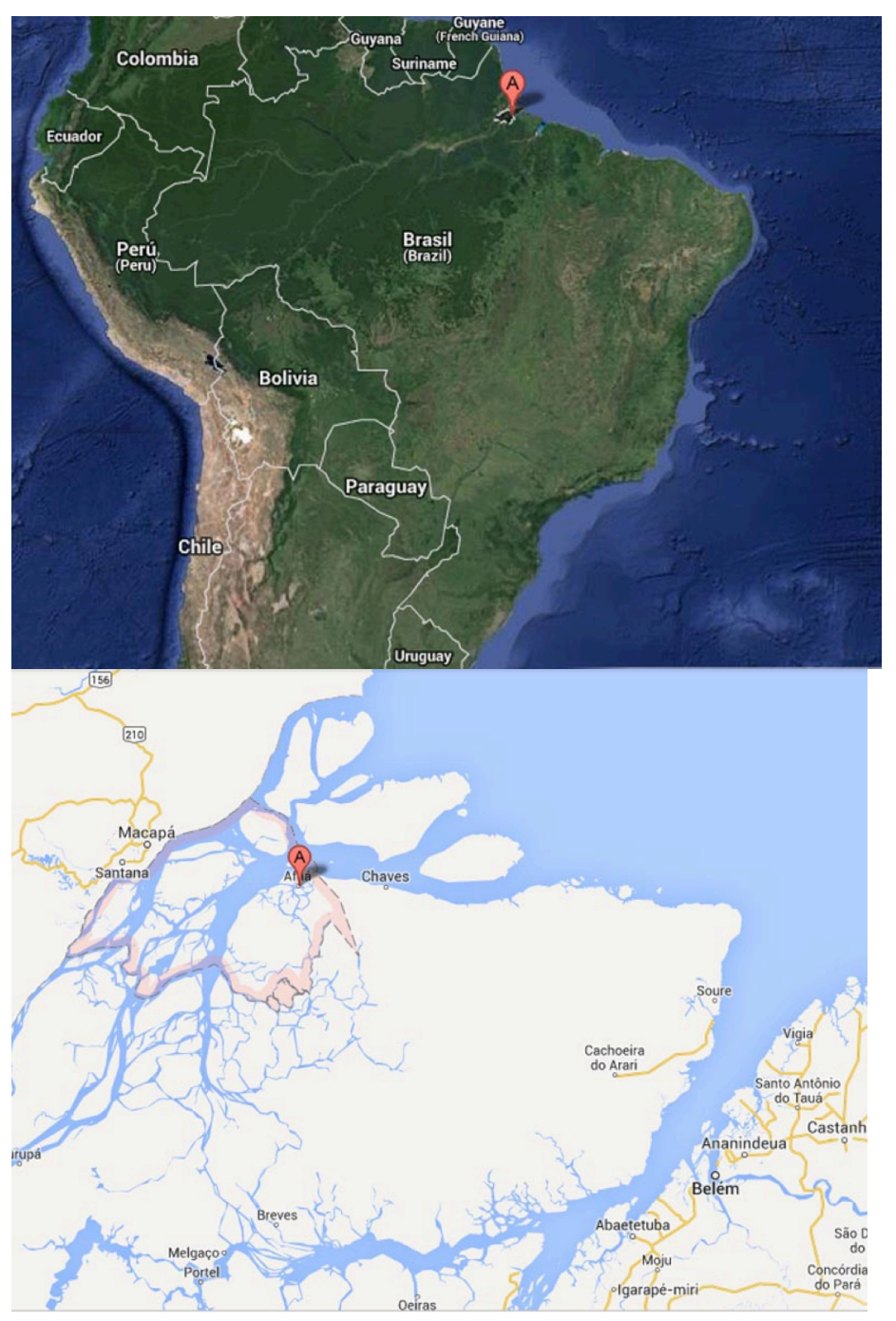

Podemos observar que Afuá se localiza na entrada do vale amazônico mais próxima ao continente europeu. Sua localização estratégica foi muito importante na implantação do 
sistema colonial português. O nome da Baía em que se localiza a cidade faz referência ao padre jesuíta Antônio Vieira, cuja atuação foi decisiva para o aldeamento de povos indígenas da região, no século XVII.

Esta apresentação inicial tem por objetivo apenas localizar o espaço geográfico da cidade na região e no país, mas, como já referido, pretendemos ir bem além dos limites imaginários dos mapas. Compreendemos cartografia como uma tarefa que exige perceber os usos atribuídos pelos sujeitos às práticas e tecnologias de comunicação. Mais que simplesmente observar o cenário desta comunidade e descrevê-lo, devemos procurar entender como essas atividades se constituem no cotidiano, a maneira como os moradores de Afuá lidam culturalmente com os meios de comunicação - mídia de massa ou hipermídia - que estão à sua disposição. E, nesse sentido, a experiência de transitar pelas ruas da cidade de Afuá é singular, pois fornece pistas desta relação entre os seus sujeitos e as mídias.

A "Veneza Marajoara", como a população local gosta de defini-la, localiza-se em uma área de várzea, inundada de acordo com o período de cheias e vazantes da Baía de Vieira Grande, composta pelo rio Afuá - que dá nome à cidade - e os rios Charapucú e Jurará (IDESP, 2012). Suas "ruas" se elevam em palafitas sobre as águas, por onde a população se desloca e estabelece suas dinâmicas. A cidade é toda construída em cima de pontes de madeiras, ou de concreto. Todas as ruas e casas da cidade são suspensas do solo:

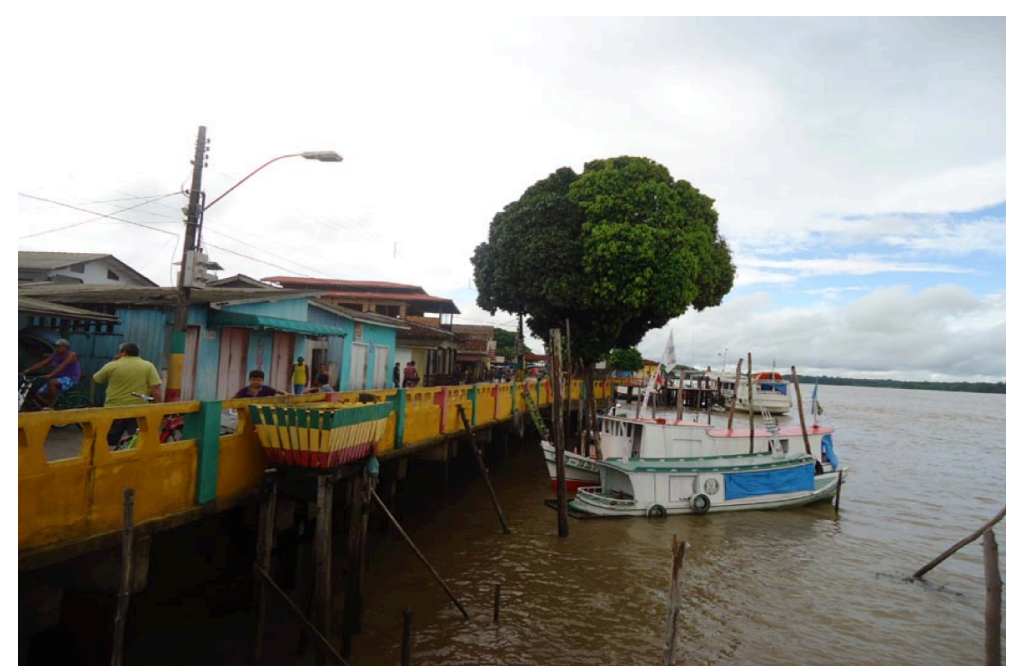

Figura 2: A orla de Afuá 


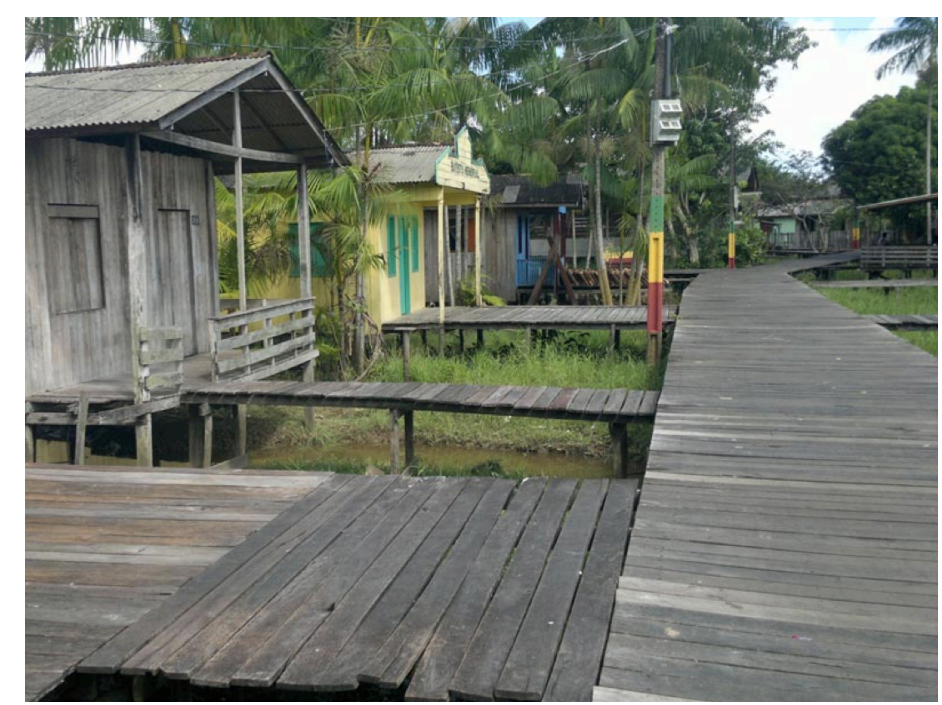

Figura 3: Rua de Afuá 1

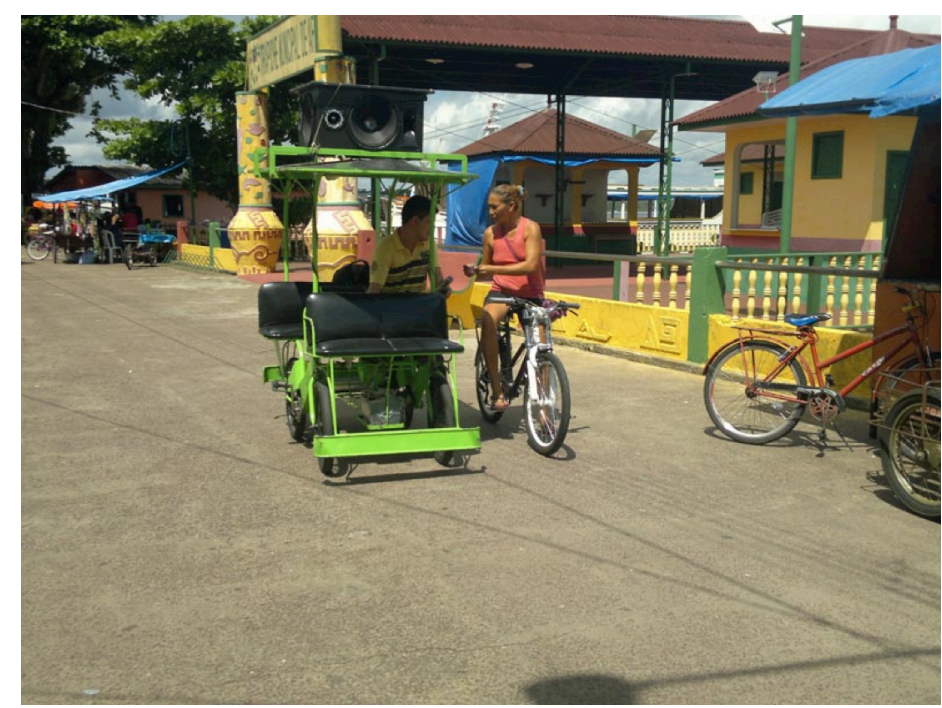

Figura 4: Rua de Afuá 2

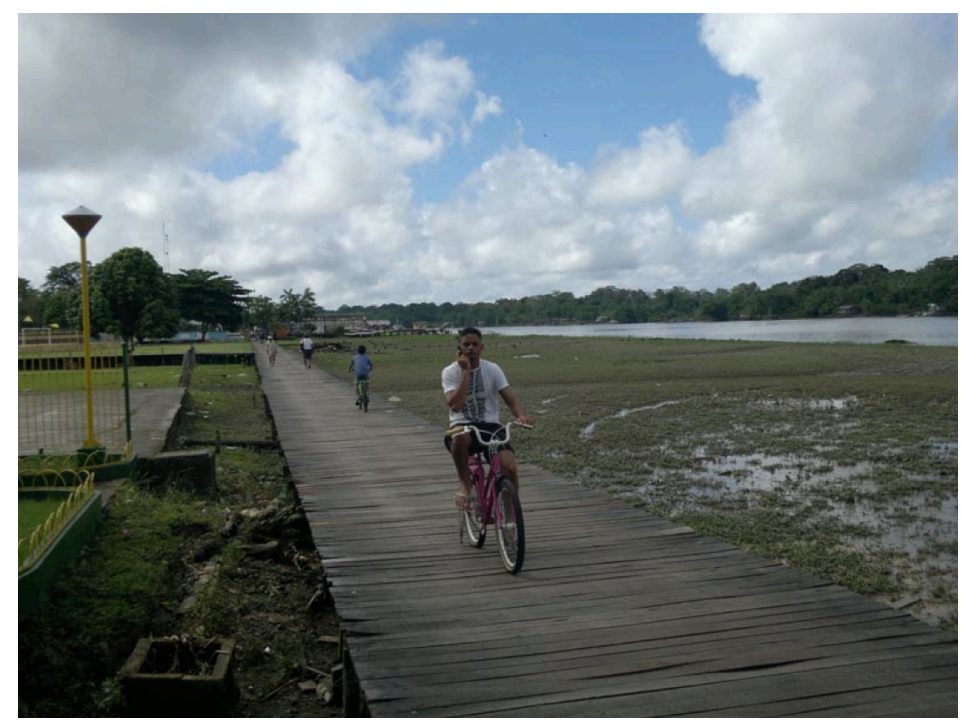

Figura 5: Rua de Afuá 3

Nestas ruas não transitam ônibus, carros, motos, tratores, conforme se pode observar nas figuras 2, 3 e 4, produzidas pelos autores. Em Afuá, só é permitido andar a pé ou de 
bicicleta é terra do bicitáxi, biciambulância. Embora seja possível identificar modelos mais ou menos sofisticados destes veículos, como todos andam de bicicleta, fica uma sensação de que não há desigualdades sociais por aqui. O que não é verdade, pois os dois bairros que dividem a cidade assinalam estas diferenças. No Centro, ficam as casas mais antigas e mais ricas, o comércio, as repartições públicas e no Capimarinho, que já se subdivide em duas partes, estão as pessoas mais pobres e os migrantes, que vivem sem muitas perspectivas econômicas na cidade.

As dinâmicas que se inscrevem nessa realidade destacam a relação que os moradores estabelecem com o rio: mesmo antes da mídia, estes eram os caminhos para a circulação de pessoas e informações, que estabeleciam e ainda estabelecem diferentes dinâmicas sociais entre os moradores do Marajó. Os próprios meios de comunicação, de qualquer natureza, chegam a Afuá pelo rio.

A geografia da cidade e do arquipélago do Marajó alimenta bastante o discurso de que as sociedades amazônicas são isoladas. De fato, existem inúmeras dificuldades para a implementação de "linhões" de eletricidade, redes de telefonia e, até mesmo, condições mínimas para o recebimento de infraestrutura para emissão do sinal de televisão ou mesmo de telefonia móvel. Isso tudo se agrava diante do desinteresse das políticas públicas do Estado Brasileiro. Num contexto acentuadamente diferente, em países como o Japão, por exemplo, o fato de ser uma ilha não representa isolamento ou problemas com infraestrutura tecnológica.

Afuá possui acesso a canais abertos de televisão, rádios locais, linhas de telefone fixo e móvel. Nos últimos quatro anos, houve a implementação efetiva de lan houses e a popularização do acesso à web. Os moradores contam que em 2007, foi criada a primeira lan house da cidade, mas ela logo fechou suas portas, porque, naquele momento, eles ainda não haviam dado sentidos sociais para os usos da internet. Realidade bem diferente em 2013. Momneto em que o interesse pela internet se traduz em várias outras experiências locais, que vão além dos espaços destas lojas de serviços.

Muitas casas do município possuem acesso à internet via rádio, por meio de provedor local e, internet via sinal de rádio. A popularização dos smartphones e do sinal de wifi possibilitaram o surgimento de outra forma de relacionamento com a rede. A internet ganhou tanta importância para a população da cidade, que em agosto de 2013, a prefeitura instalou uma praça digital com sinal de wifi aberto. Provavelmente, a primeira iniciativa desta ordem na região amazônica. Mas, ainda é cedo para avaliar os desdobramentos deste acontecimento. 
A partir das possibilidades históricas atuais destes moradores, é preciso pensar nas táticas utilizadas por eles para tornarem suas as lógicas de consumo dessas diferentes ferramentas que permitem sua interação em sociedade. É preciso pensar quais sãos as potenciais maneiras de utilização da ação comunicativa a partir das realidades e das necessidades locais: "as táticas apontam para uma hábil utilização do tempo, das ocasiões que apresenta e também dos jogos que introduz nas funções do poder" (CERTEAU, 1998, p. 102).

\section{ENTRE AS RÁDIOS E O FACEBOOK}

Nesse andar pela cidade a que nos dispusemos, percebemos como as pessoas se relacionam de maneiras diferentes com as mídias. Chegar a Afuá, pelo rio, permite ouvir ao longe o som da rádio-poste Madejus, que vai se intensificando conforme o barco se aproxima da orla da cidade. Aos poucos, ao transitar nesse espaço, pode-se perceber a forte relação dos moradores com ela: os alto-falantes, distribuídos pelas ruas de quase toda a cidade, fazem parte de seu cotidiano, há mais de 40 anos, veiculando informações e publicidade. Não é difícil perceber nos relatos das pessoas ouvidas a importância que ela ocupa em suas histórias. É rotineiro, nas ruas da cidade, enxergar pessoas ao redor das "bocas de ferro" ouvindo sua programação.

Da mesma forma, a rádio mais nova - Afuá FM - ocupa um lugar importante para a articulação das dinâmicas sociais nessa realidade. Entre seus programas mais presentes no cotidiano da população, destaca-se o "Almoçando com notícias". Durante a pesquisa, vivemos a experiência de almoçar com as famílias que nos receberam em suas casas, ouvindo coletivamente o programa e comentando as informações. Os mais jovens costumam checar as redes sociais e comentar a programação, enquanto escutam o programa.

A partir do uso da internet no município, a proximidade com as rádios, que fazia parte das práticas culturais locais, intensificou-se bastante. Os afuaenses encontraram uma maneira de aumentar sua interação com as rádios por meio do Facebook. Nos centros urbanos do mundo todo, os usos da internet vem proporcionando novas formas de interação entre os ouvintes e a rádio, principalmente a partir da disponibilização da programação nas rádio-web. Em Afuá, isso se particulariza pela relevância da rádio-poste para as pessoas da cidade.

A rede social se tornou um instrumento para aproximar os moradores da cidade do caráter de serviço que a rádio promove, por meio de recados para os radialistas, participação de sorteios, venda de produtos e rifas para apoio a obras religiosas, mensagens informativas para pessoas das áreas rurais, propaganda de pequenos e grandes comerciantes, ações 
educativas, manifestações de organizações sociais etc. Trata-se de se perceber que houve um processo de apropriação dessas possibilidades que já faziam parte das dinâmicas locais. Houve uma potencialização das interações a partir desses usos da internet.

Por meio da web, a Rádio Afuá FM amplia seus horizontes e reproduz a programação para outros municípios do Marajó e para afuaenses que estão fora, que podem participar da vida social do município por meio dessa natureza hipermidiática que foi agregada pela rádio. Ou seja, trata-se de observar o próprio movimento de convergência da cultura pelo qual passam as sociedades contemporâneas ocidentais de uma maneira geral.

\begin{abstract}
Por convergência, refiro-me ao fluxo de conteúdos através de múltiplas plataformas de mídia, à cooperação entre múltiplos mercados midiáticos e ao comportamento migratório dos públicos dos meios de comunicação, que vão a quase qualquer parte em busca das experiências de entretenimento que desejam. Convergência é uma palavra que consegue definir transformações tecnológicas, mercadológicas, culturais e sociais, dependendo de quem está falando e do que imaginam estar falando (JENKINS, 2009, p. 29).
\end{abstract}

Esta relação que estabelecem entre a rádio e o Facebook mostra como os moradores de Afuá assumem a posição de sujeitos táticos, que se organizam a partir daquilo que experienciam na cultura e utilizam conforme lógicas não estabelecidas (CERTEAU, 1998). Nesse sentido, percebemos que se trata de uma relação com a mídia que só tem sentido porque já se estabelece como bem cultural. Esse é o fator relevante para perceber os usos sociais e as táticas empregadas por esses sujeitos em relação a qualquer experiência midiática. Em relação às manifestações de protesto de junho e julho de 2013, as singularidades destes sujeitos estiveram presentes a partir de suas práticas culturais, nas interações que estabeleceram com a mídia.

\title{
SUBJETIVIDADES E MANIFESTAÇÕES
}

As experiências dos protestos políticos pelas quais o Brasil passou - e ainda passa neste ano de 2013, percebemos que há uma série de particularidades quanto aos seus acontecimentos. Quando chamamos a esse movimento de "Primavera Brasileira", estabelecemos uma rede de sentidos entre a série de protestos, manifestações e passeatas políticas que marcaram o início dos anos 2010: um movimento revolucionário de insatisfação destas sociedades, que se articulou por meio da web, ganhou as ruas e levou uma multidão a mostrar seu descontentamento com governos de diferentes países no Oriente Médio. 
Apesar dos veículos jornalísticos ao redor do planeta destacarem que o sucesso desse movimento se deve pela articulação das pessoas pela rede mundial de computadores, é preciso ter clareza de que a web não é o fator exclusivo para seu estabelecimento. A rede teve um papel relevante, mas não se trata apenas de uma questão de tecnologia: "A internet é uma condição necessária, mas não suficiente. As raízes da rebelião estão na exploração, opressão e humilhação" (CASTELLS, 2011, s/p).

De forma semelhante, mas por razões diferentes, o cenário político brasileiro também foi agitado nos últimos meses. Os protestos que se iniciaram no eixo Rio-São Paulo tiveram suas bases iniciais articuladas na web e logo se propagaram por outras capitais e cidades e levaram uma multidão às ruas. Mas as insatisfações coletivas é que são o combustível para o desenvolvimento destes acontecimentos: primeiro, os manifestantes, em sua maioria jovens de classe média, reivindicaram melhorias no transporte público contra o reajuste das tarifas de ônibus e, em um segundo momento, clamou-se por qualidade de vida: reformas qualitativas relacionadas à saúde, educação, moradia, saneamento etc.

Inicialmente, tudo aconteceu por meio da interação através da internet e, sobretudo, pela rede social Facebook. Daí um dos principais slogans das manifestações "Saímos do Facebook!". A rede possibilitou debates preliminares que levaram os manifestantes a reeditar mais um movimento que ocupou as ruas, avenidas e praças de várias cidades do Brasil. E, da mesma maneira como aconteceu no Oriente Médio, as manifestações sociais e políticas brasileiras logo ganharam novos espaços de visibilidade, além da internet, pois, diferente do que aconteceu no Oriente Médio, foram agenciadas para o mundo inteiro, por meio das grandes corporações de comunicação brasileiras.

Apesar das semelhanças, existem diferenças significativas entre as Primaveras. Enquanto no Oriente Médio as mídias sociais eram as principais fontes de notícias para a mídia internacional (HOWARD, 2011), no Brasil, as movimentações ganharam grandes coberturas dos grupos jornalísticos nacionais, como Rede Globo, Bandeirantes, Record etc. Como a programação televisiva, no Brasil, e sua convergência com a rede mundial de computadores ainda é a principal fonte de informação dos brasileiros, estes acontecimentos alcançaram mais rapidamente todo o território nacional e foram além do Facebook.

A TV está presente em aproximadamente 95\% dos lares brasileiros, enquanto a internet alcança uma margem pouco maior que 30\% (IBGE, 2012). Acreditamos, por isso, que parte da repercussão dos protestos no Brasil ganhou visibilidade pelo lugar que ocupou na mídia massiva, sobretudo televisiva: os protestos se renovaram e a cobertura motivou novos 
levantes em diferentes regiões do território nacional. Ou seja, em um país como o nosso, em que a programação televisiva ocupou - e ainda ocupa - um lugar estratégico para a construção de nossas identidades e nossas verdades sociais.

Assim, ainda que as origens desses movimentos sociais tenham constituído suas ações a partir do potencial comunicativo que existe na internet (LEMOS, 2010), é impossível deixar de considerar que os manifestantes são sujeitos históricos, atravessados por diferentes e por vezes contraditórios discursos, agenciados pelos diferentes meios de comunicação. Para Rosário Gregolin:

Seria redutor entender que há apenas passividade diante do agenciamento coletivo da subjetividade; pelo contrário, há pontos de fuga, de resistência, de singularização. Não há, nos discursos da mídia, apenas reprodução de modelos - ela também os reconstrói, reformata, propõe novas identidades. Ao mesmo tempo, há uma tensa relação entre a mídia e seus leitores: a subjetividade é fabricada e modelada no registro social, mas os indivíduos vivem essa subjetividade tensivamente, reapropriando-se dos componentes fabricados e produzindo a singularização, criando outras maneiras de ser. Se só houvesse submissão, não haveria produção de novos sentidos. Acontece que não há agenciamento completo das forças de territorialização e as de desterritorialização, ambas agindo e provocando contradições (GREGOLIN, 2007, p. 24):.

Podemos observar, nestas manifestações, diferentes processos de interação, várias plataformas de comunicação. Todas elas, no entanto, são traduções da história e da cultura destas sociedades, profundamente marcadas por processos locais. Embora se constituam a partir de algumas recorrências, o descontentamento em relação ao Estado, os manifestantes do Egito levantaram bandeiras diferentes daquelas flamejantes na Avenida Paulista, que por sua vez são bem diferentes dos protestos em relação à Batalha Camaroeira em Afuá, em julho de 2013.

\section{ACONTECIMENTOS EM AFUÁ}

Nos últimos oito anos, a sociedade de Afuá produziu um espetáculo cultural a partir de propostas do governo municipal, a Batalha Camaroeira. O evento se tornou uma das atrações principais do Festival do Camarão, que acontece todo mês de julho na cidade. /a organização, os ensaios, o clima de competição da Batalha passaram a fazer parte integrante da cultura popular no município. Ela entrou na agenda de atividades municipais e, todo ano, atrai turistas da região e do Brasil para a cidade. A realização da Batalha acontece aos moldes de outros espetáculos já bastante celebrizados pela mídia, como as disputas dos Bois, em Parintins, ou dos Botos do Sairé, no interior da região amazônica. 
A Batalha em que se envolvem os dois blocos de camarão é uma manifestação cultural que tem como característica movimentar toda a comunidade pelo sentimento de pertença, de identificação. De um lado, quase metade da população faz parte do Camarão Convencido, cujos adereços verdes representam o camarão cru. A outra metade participa do Camarão Pavulagem e suas cores predominantemente vermelhas, fazem alusão ao camarão frito. Ambos traduzem parte da cultura local e suas práticas alimentares como a grande produção e consumo de camarão na região. No início de julho, durante a realização de parte da pesquisa empírica, no período que antecedia o Festival do Camarão, era comum ver as pessoas trabalhando e se organizando em função da Batalha.

Diferente do que aconteceu na primeira visita de campo, quando a Batalha ainda estava distante de acontecer, os participantes dos dois blocos fizeram questão de nos mostrar suas rivalidades. Como estratégia, os dois grupos por meio dos, onde indicavam que seu grupo seria o vencedor e diminuíam a qualidade do outro. A todo instante eram retomadas as memórias das batalhas anteriores. Como bem cabe a estas práticas sociais, evidenciavam quem havia vencido mais a competição e nos mostravam os enredos de cada, para que julgássemos qual, de fato, era o melhor. Nem podíamos pensar em escolher um dos blocos, isso nos tornaria, pelo menos naquele período, inimigo de metade da cidade.

Nesta segunda visita, houve um desentendimento entre a administração municipal e as organizações das associações culturais responsáveis pelos blocos que realizam o espetáculo. Como a prefeitura não repassou a verba de apoio para a confecção das fantasias e alegorias, as organizações culturais ficaram muito endividadas e sem condições de realizar o desfile dos dois blocos. Mesmo diante deste impasse, até a semana que antecedeu o Festival do Camarão, elas protelaram a decisão de não realizar o espetáculo da Batalha ano de 2013.

Antes de anunciarem o cancelamento da Batalhas, cada organização convocou uma reunião deliberativa para não realizar o espetáculo. Depois da decisão tomada, as lideranças forma às rádios locais comunicar o posicionamento para a população. De imediato, tanto nas ruas como no Facebook, essa decisão provocou inúmeras e acaloradas discussões. Parte da população acusava a prefeitura e outra parte defendia, alegando que a administração anterior havia falido os cofres públicos. Nas páginas da Rádio Afuá FM forma postadas tantas mensagens de indignação, que a administração da emissora foi obrigada a retirá-la do ar, momentaneamente.

Essa movimentação obrigou a administração municipal a se posicionar diante da população e, assim como os grupos, o prefeito de Afuá também se utilizou desses 
movimentos para expor o posicionamento da administração municipal sobre a Batalha Camaroeira. Ele não se posicionou nas redes sociais, mas fez um pronunciamento nas rádios. Para ele, a prefeitura não tinha como arcar, naquele momento, pois havia outras prioridades, inclusive o pagamento da folha salarial do município. Ele alegava que a responsabilidade da não realização era das organizações de cada grupo, pois realizaram gastos além do que podiam.

Apenas este cenário de disputas entre as associações e a administração gerou inúmeras dinâmicas, com posicionamentos, afirmações e retratações de sujeitos e instituições, com postagens agressivas e apagamentos das mensagens, em ambientes on e offline, tudo de forma extremamente rápida. $\mathrm{E}$, como conseqüência, houve um momento de união entre os grupos rivais para a organização de um protesto político contra a administração municipal a ser realizado no dia de abertura do evento.

Nesse sentido, ao pensar em formas de organizar um ato de protesto, entre os relatos ouvidos foi recorrente ouvir as pessoas tomarem como referência as manifestações políticas da Primavera Brasileira assistidos pela televisão - sobretudo pela Rede Globo. E a ressalva dessa articulação recaia sobre os noticiados atos de vandalismo e violência exibidos pelas reportagens jornalísticas. Os moradores desejavam que fosse uma manifestação pacífica e simbólica, para que não acontecesse da mesma forma como assistiam às manifestações da nas grandes cidades brasileiras e, sobretudo, as repressões agressivas da polícia sobre a população.

Quando o movimento tomou mais força, na cidade, outras questões além da Batalha Camaroeira foram levantadas pelos manifestantes. A pauta das reivindicações na cidade Afuá eram variadas: abastecimento dos remédios do posto de saúde, melhorias no abastecimento de água e energia, mas, sobretudo, melhores condições salariais para os profissionais da educação. Uma das particularidades do movimento na cidade diz respeito à atuação do professores, que, diferente do que aconteceu nas grandes cidades, como são os organizadores da Batalha Camaroeira, foram os principais sujeitos envolvidos nas manifestações locais.

Em uma conversa informal, uma das lideranças do movimento, professor do município, evidenciou o pouco envolvimento da população, que só no momento inicial, quando foi suspensa a Batalha, reagiu. Depois, quando os protestos foram se estendendo às questões da infraestrutura local, o pouco apoio solidário aos manifestantes foi enfraquecendo. De acordo com ele, poucos professores se envolveram, pois muitos vivem em regime de contrato provisório com a Prefeitura. Ele lamentou bastante a oportunidade de melhorar as 
condições do ensino na cidade. O professor frisou bastante que mesmo a população do bairro Capimarinho - o bairro mais novo e que concentra a periferia da cidade - pouco se envolveu e perdeu a oportunidade de lutar para melhorar as condições de habitação.

Diante da promessa da Prefeitura de uma possível liberação de verbas para a realização da Batalha posteriormente, as discussão sobre o tema ficaram mais espaças. No final de setembro, durante outra visita à cidade, embora bastantes frustrados, os participantes já assumiam que em 2013 não haveria o espetáculo em Afuá. Inegavelmente, há entre eles um descontentamento em relação às atitudes da Prefeitura e em 2014, novos acontecimentos devem envolver o poder público a as organizações dos dois blocos, que provavelmente serão mediados pelas rádios locais e pelas páginas do Facebook.

\section{CONSIDERAÇÕES FINAIS}

Essa movimentação exemplifica como o processo de convergência cultural, do qual Jenkins fala, está acontecendo em Afuá a exemplo de qualquer centro urbano na contemporaneidade. Não apenas demonstra a relação que os moradores estabeleceram com as manifestações políticas que ocorreram em todo território nacional, como também apresenta a experienciação deles com essa informação entre os diferentes meios.

Essa dinamicidade é percebida inclusive pelos próprios moradores da cidade. Entre os relatos mais significativos está a percepção de Manoel Jardim, integrante da organização do Camarão Convencido, sobre o acontecimento. Para ele, há poucos anos atrás, seria impensável toda essa agilidade em deliberar as demandas da associação cultural, pois seria necessário convocar os integrantes individualmente, indo de porta em porta. Mesmo que a rádio auxiliasse com avisos na programação, não alcançaria as pessoas da forma como acontece agora. Hoje, essa dinâmica tem facilitado a organização das atividades em Afuá, permitindo que as pessoas possam se organizar e participar com muito mais facilidade das associações culturais e qualquer outra atividade social.

Essa realidade ilustra a proposta das táticas que são empregadas pelos sujeitos locais:

A presença ou a circulação de uma representação (ensinada como o código da promoção sócio-econômica por pregadores, por educadores ou por vulgarizadores) não indicam de modo algum o que ela é para seus usuários. É ainda necessário analisar a sua manipulação pelos praticantes que não a fabricam. Só então é que se pode apreciar a diferença ou a semelhança entre a produção da imagem e a produção secundária que se esconde nos processos de sua utilização (CERTEAU, 1998, p. 40). 
Apesar de os protestos não conseguirem ter a expressão que os moradores de Afuá desejavam, esse acontecimento pôde nos evidenciar como o processo de convergência cultural proposto por Jenkins é um fenômeno amplo e global, sobre certos aspectos. Ainda que para o estabelecimento da convergência sejam necessárias condições mínimas de estrutura, essa dinâmica é um processo que vai além da simples utilização da tecnologia, pois está concentrado sobre os usos que as pessoas implicam a essas ferramentas em seu cotidiano. Nesse sentido, mais que a internet e os aparelhos que permitem o acesso à web, é para perceber os acontecimentos de julho de 2013 em Afuá, precisamos direcionar nossos olhos e ouvidos para perceber as experiências dos moradores da cidade.

Afuá é uma cidade latinoamericana, localizada em um país onde a programação televisiva ocupa o lugar central. No Brasil, há uma intensa convergência entre as redes sociais e a televisão. Os dados do IBOPE revelam, por exemplo, que os acessos ao Facebook, no Brasil, estão muito próximos ao número de acessos da globo.com e chegam a mais de 46 de milhos diariamente (GRIPA, 2013). Em função das singularidades culturais da cidade de Afuá, como vimos, os usos do Facebook também convergem intensamente com a programação das rádios locais. Mas como o próprio Jenkins alerta:

\footnotetext{
Nem todos os participantes são criados iguais. Corporações - e mesmo indivíduos dentro das corporações da mídia - ainda exercem maior poder do que qualquer consumidor individual, ou mesmo um conjunto de consumidores. E alguns consumidores têm mais habilidades para participar dessa cultura emergente do que outros (JENKINS, 2009, p. 31).
}

Suspeitamos que essas diferentes formas de se relacionar com as tecnologias impliquem no estabelecimento de outras formas de organização das disputas de poder na comunidade e interfira diretamente na interação entre esses sujeitos. Mas é necessário outros esforços para aprofundar ainda mais a experiênciação dessa realidade empírica.

\section{REFERÊNCIAS}

CASTELLS, Manuel. Castells, sobre internet e rebelião: "É só o começo" (entrevista). In Outras palavras. Disponível em: $<$ http://outraspalavras.net/posts/castells-sobre-internet-einsurreicao-e-so-o-comeco/>. Acesso em: 07 de janeiro de 2013.

CERTEAU, Michel de. A invenção do cotidiano: artes de fazer (vol.1). $3^{\text {a }}$ edição. Petrópolis, RJ: Editora Vozes, 1998. 
FRANÇA, Vera. Paradigmas da comunicação: conhecer o que? X COMPÓS: Brasília, DF. 2001. Disponível em: $<$ http://www.compos.org.br/data/biblioteca_1266.pdf $>$. Acesso em: 13 de março de 2012.

GOMES, Pedro Gilberto. O processo de midiatização da sociedade e sua incidência em determinadas práticas sociossimbólicas na contemporaneidade: a relação mídia e religião. In FAUSTO NETO [et al]. Midiatização e processos sociais na América Latina. São Paulo: Paulus, 2008.

GREGOLIN, Maria do Rosário. Análise do Discurso e mídia: a reprodução das identidades. Revista Comunicação, Mídia e Consumo, São Paulo, Vol. 4, No11, 2007.

GRIPA, Marcelo. Brasil é o $2^{\circ} \mathbf{~ e m ~ a c e s s o ~ d i a ́ r i o ~ a o ~ F a c e b o o k . ~ O l h a r ~ D i g i t a l , ~ U O L , ~ B r a s i l . ~}$ 2013, 12 de novembro. Disponível em: $<$ http://olhardigital.uol.com.br/noticia/37493/37493>. Acesso em: 24 de setembro de 2013.

HOWARD, Philip N. The Arab Spring's Cascading Effects. Pacif Standard, Los Angeles (USA). February 23, 2011. Disponível em: $<$ http://www.psmag.com/politics/the-cascadingeffects-of-the-arab-spring-28575/>. Acesso em: 07 de janeiro de 2013.

IBGE - Instituto Brasileiro de Geografia e Estatística. Censo Demográfico 2010: Resultados gerais da amostra (Afuá-PA). IBGE Cidades 2010. Disponível em:

$<$ http://cidades.ibge.gov.br/xtras/perfil.php?lang=\&codmun=150030\&search=para|afua $>$. Acesso em: 05 de dezembro de 2012.

IBGE - Instituto Brasileiro de Geografia e Estatística. Síntese de indicadores sociais: Uma análise das condições de vida da população brasileira. IBGE, Rio de Janeiro, 2012. Disponível em: $<$ ftp://ftp.ibge.gov.br/Indicadores_Sociais/Sintese de Indicadores_Sociais_2012/SIS 2012.pdf>. Acesso em: 15 de junho de 2013.

JENKINS, Henry. Cultura da convergência. 2. ed. São Paulo: Aleph, 2009.

LEMOS, André. Cibercultura: tecnologia e vida social na cultura contemporânea. 5. ed. Porto Alegre: Sulina, 2010.

MARTÍN-BARBERO, Jesús. Ofício de cartógrafo: travessias latino-americanas da comunicação na cultura. São Paulo: Edições Loyola, 2004.

Original recebido em: 03/02/2009

Aceito para publicação em: Novembro de 2013

Resumo sobre os autores

Ivânia dos Santos Neves Doutorado em Linguística, na área de Análise do Discurso pela Unicamp (2009). Mestrado em Antropologia pela Universidade Federal do Pará (2004). Licenciatura em Letras pela 
Universidade Federal do Pará (1992).

Prêmio Jabuti 2000, na categoria didático. Experiências na área de Antropologia, Lingüistica e

Comunicação. Desenvolve pesquisas com sociedades indigenas Tupi e experimentações didáticas com as novas tecnologias da informação. Atualmente, é docento do Programa de Pós-Graduação em Comunicação, Cultura e Amazônia da Universidade Federal do Pará.

Diogo Silva Miranda De Miranda

Bacharel em Comunicação Social (jornalismo), pela UFPA, especialista em Jornalismo Digital, pela

UNINTER. Bolsista Capes e discente do Programa de Pós-Graduação Comunicação, Cultura e Amazônia (PPGCom/UFPA). 